\title{
Five-year results of a controlled study of BCG immunotherapy after surgical resection in bronchogenic carcinoma
}

\author{
JW Millar, P ROSCOE, SJ PEARCE, S LUDGATE, NW HORNE \\ From the Chest Unit and Department of Respiratory Medicine, City Hospital, Edinburgh
}

ABSTRACT Ninety-two patients with histologically confirmed bronchogenic carcinoma treated by surgical resection of the tumour were subsequently given immunotherapy with BCG (Glaxo). The patients were randomly allocated into three groups. Twenty-nine patients received multipuncture BCG (50 to $250 \times 10^{6}$ viable units), and twenty-six patients intradermal BCG $\left(0.4\right.$ to $0.9 \times 10^{6}$ viable units), treatment being given at $1,2,5,9,13,26$, and 52 weeks after operation. Thirty-seven control patients did not receive any BCG immunotherapy; two patients in the control group were lost to follow-up. The overall five-year survival in all groups was $37 \%$. Favourable prognostic features were squamous carcinoma ( $45 \%$ five-year survival), the absence of involved mediastinal nodes at operation $(46 \%)$, and lobectomy $(45 \%)$, but even the presence of involved mediastinal nodes was associated with a $19 \%$ five-year survival. There were no statistically significant differences between the survival of the control group and either group treated by immunotherapy considered individually or in combination. The influence of the presence of positive mediastinal lymph nodes and the extent of surgical resection on survival was not affected by immunotherapy. No serious side-effects of immunotherapy were encountered.

Surgery remains the treatment of choice in patients with bronchogenic carcinoma although only a minority of patients are suitable for radical resection. Even in this group the five-year survival figures range from $20 \%$ to $40 \%$ in most series and there has been little change in these results in recent years. ${ }^{1}$ Tumour recurrence accounts for almost all of this high mortality and therefore postoperative adjuvant therapy has been advocated to eradicate residual tumour deposits. As early as 1929 Pearl stated that "florid tuberculosis and malignant tumours occur together in the same individual only with great rarity" and reviewed animal experiments which showed that the rate of tumour growth was inhibited by active tuberculosis. ${ }^{2}$ More recently the value of Bacillus Calmette-Guerin (BCG) in preventing or inhibiting the growth of tumours in animal models has been described, ${ }^{34}$ and encouraging clinical

Address for reprint requests: Dr JW Millar, Chest Unit, City Hospital, Greenbank Drive, Edinburgh EH10 5SB. results have been observed using BCG immunotherapy in acute lymphoblastic leukaemia ${ }^{5}$ and malignant melanoma ${ }^{6}{ }^{7}$ although subsequent studies have given somewhat conflicting results. ${ }^{8} 9$

The theoretical basis of non-specific immunotherapy of lung cancer has been reviewed by Israel in $1973^{10}$ and in subsequent years several trials of non-specific BCG immunotherapy in bronchogenic carcinoma have been reported and comprehensively reviewed by Hersh, Gutterman, and Mavligit. ${ }^{11}$ The various timing, doses, and routes of administration of BCG in these studies have included a single postoperative intrapleural ${ }^{12}$ or subdermal ${ }^{1314}$ injection of BCG, and preoperative intralesional injection of BCG. ${ }^{15}$ Initial results of these studies have been promising but few trials have yet been completed with full details of five-year survival figures. We now report the five-year results of a prospective controlled trial of repeated BCG non-specific immunotherapy given intradermally and subcutaneously in 92 unselected patients with bronchogenic carcinoma treated by surgical resection, the early results of which were first reported in $1977 . .^{16}$ 


\section{Methods}

Ninety-two patients with histologically proven bronchogenic carcinoma were entered into the study over 18 months. After routine preoperative assessment of fitness for operation all patients underwent surgical resection of the primary tumour. Metastases at the time of assessment were excluded clinically and by barium swallow examination, four patients in addition having negative radioisotope bone or liver scans. All resections were performed by the same surgical team using a uniform technique. The presence of ipsilateral malignant nodes did not preclude resection and mediastinal and hilar nodes were biopsied routinely in every case and examined histologically. Informed consent was obtained before entry to the study.

\section{BCG IMMUNOTHERAPY}

After successful resection patients were randomly allocated to one of three groups: (1) control groupno BCG immunotherapy, a placebo vaccination was not used; (2) intradermal group - $0.1 \mathrm{ml}$ BCG Glaxo $\left(0.4\right.$ to $0.9 \times 10^{6}$ viable units) by standard intradermal injection into the outer aspect of upper arm; (3) multipuncture group-3 mg percutaneous BCG Glaxo (50 to $250 \times 10^{6}$ viable units) diluted with $0.15 \mathrm{ml}$ distilled water and applied to outer aspect of the upper arm. A multipuncture gun was then fired to a depth of $2 \mathrm{~mm}$ on two occasions into five adjacent sites (200 punctures). The BCG immunotherapy was administered in both groups at 1, 2, 5, 9, 13, 26, and 52 weeks after resection.

\section{ASSESSMENT}

All patients including controls were reviewed at the above time intervals and subsequently at six-monthly to yearly intervals until five years after operation. Palliative treatment with radiotherapy was given to all groups when appropriate for treatment of recurrent disease. The time and clinical cause of death was established in all cases. All patients surviving five years were clinically and radiographically free of disease at their five-year review.

Statistical analysis of median survival time and five-year survival rate was performed by the Wilcoxon Rank Sum test and the Log Rank test.

\section{Results}

Previous results of the immunological assessment of these patients have already been reported, 1718 and the results presented here are solely concerned with clinical details and five-year survival figures. Two patients in the control group were lost to follow-up after one year and have been excluded from further analysis, leaving a total of 90 patients available for analysis.

The 90 patients had an age range $30-72$ years (mean 60 years) there being no differences between the three groups. Patient details are summarised in table 1 . The three groups were comparable except for a predominance of squamous carcinoma in the intradermal group. The term "undifferentiated carcinoma" includes both large and small cell undifferentiated carcinomas.

The cause of death could not be assessed accurately in all patients as many died at home and did not have necropsies, but all patients who died, except one in the multipuncture group who died of a cerebral haemorrhage, had clinical evidence of recurrent disease often with widespread metastases.

The constructed life tables for the 90 patients are illustrated in the figure. Although the median survival time for the intradermally treated group was 39 months compared to 24 months for both control and multipuncture groups, this was not statistically significant $(p>0.05)$. Similarly, the differences in the overall five-year survival figures of $41 \%$ in the multipuncture treated group, $31 \%$ in the intradermal treated group, and $37 \%$ in the control group, were not statistically significant ( $p>0.05$ ).

The overall five-year survival in all 90 patients was $37 \%$, favourable prognostic features being squamous carcinoma ( $45 \%$ five-year survival) as opposed to undifferentiated carcinoma $(27 \%)$; and lobectomy $(45 \%)$ rather than pneumonectomy $(28 \%)$. When

Table 1 Patient details

\begin{tabular}{|c|c|c|c|c|}
\hline & Total & Control & $M P B C G$ & $I D B C G$ \\
\hline $\begin{array}{l}\text { Number } \\
\text { Histology }\end{array}$ & 90 & 35 & 29 & 26 \\
\hline $\begin{array}{l}\text { Squamous } \\
\text { Undifferentiated }\end{array}$ & $42(47 \%)$ & $15(43 \%)$ & $12(41 \%)$ & $15(58 \%)$ \\
\hline $\begin{array}{l}\text { Total } \\
\text { Large cell } \\
\text { Small cell } \\
\text { Adenocarcinoma } \\
\text { Positive mediastinal nodes } \\
\text { Lobectomy } \\
\text { Pneumonectomy }\end{array}$ & $\begin{array}{l}41(46 \%) \\
26(29 \%) \\
15(17 \%) \\
7(7 \%) \\
32(36 \%) \\
47(52 \%) \\
43(48 \%)\end{array}$ & $\begin{array}{l}17(49 \%) \\
13(37 \%) \\
4(12 \%) \\
3(8 \%) \\
13(37 \%) \\
21(60 \%) \\
14(40 \%)\end{array}$ & $\begin{array}{l}16(55 \%) \\
9(31 \%) \\
7(24 \%) \\
1(4 \%) \\
10(34 \%) \\
14(48 \%) \\
15(52 \%)\end{array}$ & $\begin{array}{l}8(31 \%) \\
4(15.5 \%) \\
4(15 \cdot 5 \%) \\
3(11 \%) \\
9(35 \%) \\
12(46 \%) \\
14(54 \%)\end{array}$ \\
\hline
\end{tabular}




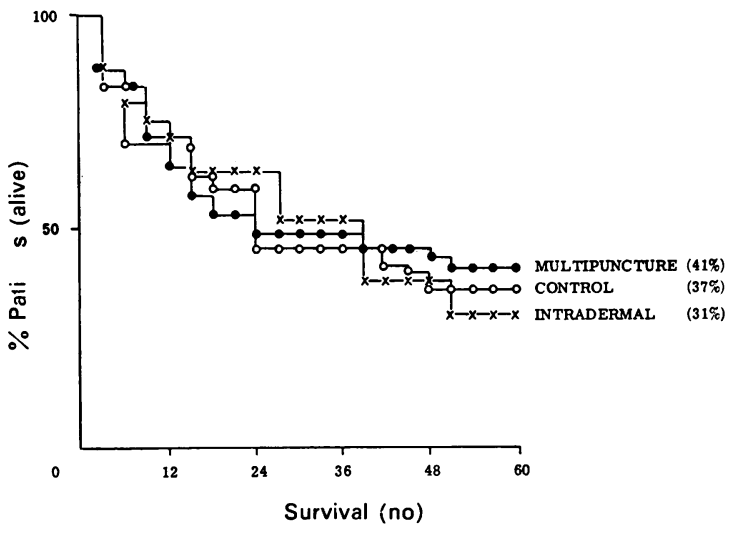

Figure Effect of BCG immunotherapy on prognosis after surgical resection of bronchogenic carcinoma in 90 patients.

routinely biopsied mediastinal nodes were free of tumour the overall five-year survival was $46 \%$ but even when these nodes were positive $19 \%$ patients survived five years. When the intradermal and multipuncture groups are considered together as an "immunotherapy" group and compared directly with the control group, no significant difference could be demonstrated in the various subgroups of patients (table 2).

Side effects caused by BCG immunotherapy were very uncommon and encountered only in the multipuncture group. Four patients had a "flue-like" illness developing within 24 hours of the multipuncture ECG and persisting for up to 72 hours.

The changes in the extent of the Mantoux reaction in patients during the study are shown in table 3 . Eleven patients receiving BCG were initially anergic but all subsequently converted. Tw'o of the four patients initially anergic in the control group remained anergic, one patient died at 12 weeks and the other at three years.

\section{Discussion}

This study has failed to demonstrate a significant
Table 3 Effect of BCG immunotherapy on Mantoux reaction $(10 \mathrm{TU})$

\begin{tabular}{|c|c|c|c|}
\hline & Control & $M P B C G$ & $I D B C G$ \\
\hline $\begin{array}{l}\text { Mean increase in } \\
\text { reaction }(\mathrm{mm})\end{array}$ & $\begin{array}{l}1 \cdot 8 \\
\text { NS }\end{array}$ & $\begin{array}{l}12.1 \\
p<0.05\end{array}$ & $\begin{array}{l}12.8 \\
p<0.05\end{array}$ \\
\hline
\end{tabular}

increase in survival rates in patients with operable bronchogenic carcinoma when BCG immunotherapy was given in the regimens described.

This failure may in part be caused by the relative inertness of bronchogenic carcinoma in the immunological sense and its absence of readily demonstrable tumour antigens. These features of lung cancer may make it less amenable to attack by immunologically stimulated cells such as $\mathrm{K}$ cells and macrophages than other tumours in which more favourable responses to immunotherapy have been demonstrated. However, the many variables in the choice of a regimen of immunotherapy are s.ıch that the dosage, timing, and frequency of treatment we have used may be inappropriate to achieve maximal immunological activity against residual tumour cells. The complexity of these factors and the lack of suitable animal models corresponding to human bronchogenic carcinoma make the selection of an immunotherapeutic regimen difficult. It has been suggested that there may be a difference in immunogenic effect between the various strains of BCG when used in man. Mathé maintains that only a strain which maintains a chronic BCG-itis is effective and that fresh living Pasteur BCG is the only strain which does this regularly, ${ }^{19}$ but Muggleton and Hilton, in studies with several immunogenic tumours in laboratory animals, were unable to show any difference between the immunotherapeutic effects of the Glaxo, Pasteur, or Danish strains of BCG (personal communication). The dosis of ECG used in this trial are comparable to those employed by McKneally ${ }^{12}$ and Edwards ${ }^{14}$ but both these investigators have used a single dose in contrast to our regimen of repeated doses. The timing of immunotherapy postoperatively may be important but there

Table 2 Influence of immunotherapy on five-year survival of subgroups of patients with bronchogenic carcinoma when compared with controls

\begin{tabular}{|c|c|c|c|c|}
\hline & \multicolumn{2}{|c|}{ Immunotherapv } & \multicolumn{2}{|c|}{ Cortrol } \\
\hline & $n$ & $\%$ & $n$ & $\%$ \\
\hline $\begin{array}{l}\text { All patients } \\
\text { Operation } \\
\text { Histology } \\
\text { Extent }\end{array}$ & $\begin{array}{r}20 / 55 \\
10 / 26 \\
10 / 29 \\
10 / 27 \\
8 / 24 \\
3 / 19 \\
17 / 36\end{array}$ & $\begin{array}{l}36 \% \\
46 \% \\
34 \% \\
37 \% \\
33 \% \\
16 \% \\
47 \%\end{array}$ & $\begin{array}{r}13 / 35 \\
9 / 21 \\
4 / 14 \\
9 / 15 \\
3 / 17 \\
3 / 13 \\
10 / 22\end{array}$ & $\begin{array}{l}37 \% \\
43 \% \\
29 \% \\
60 \% \\
18 \% \\
23 \% \\
45 \%\end{array}$ \\
\hline
\end{tabular}


is little experimental work to indicate the most suitable interval. The route of administration may be of major importance. Edwards, ${ }^{14}$ like us, employed distant dermal injection, while McKneally ${ }^{12}$ used the intrapleural route to involve lymphatic drainage to the affected area and has emphasised the importance of this approach. More recently Holmes ${ }^{15}$ has taken this one step further with direct intralesional injection of BCG before operation while we have used a similar technique in the treatment of irresectable bronchogenic carcinoma. ${ }^{20}$ These approaches allow many new regimens of immunotherapy to be planned but unfortunately such studies are necessarily protracted and experience has shown that early encouraging results can be misleading. The results of further trials in the field of bronchogenic carcinoma and other human tumours will become available within the next few years and it may then be possible to shed further light on the possible role of immunotherapy in the treatment of bronchogenic carcinoma.

We would like to thank Dr PW Muggleton and Mrs Brenda Mullinger of Glaxo Group Research Limited for advice in setting up the study and for providing the vaccine, and to Mr RJM McCormack and $\mathrm{Mr}$ PR Walbaum of the City Hospital, Edinburgh, and Dr RN Johnston and Dr DH Smith of King's Cross Hospital, Dundee for allowing us to study their patients. We are grateful to Miss $\mathbf{J}$ Holywell for secretarial help.

\section{References}

${ }^{1}$ Crofton JW, Douglas AC. Respiratory diseases. Second edition. London: Blackwell, 1975:583.

${ }^{2}$ Pearl R. Cancer and tuberculosis. Am J Hyg 1929;9:97159.

${ }^{3}$ Zbar B, Rapp HJ, Ribi EE. Tumor suppression by cell walls of myobacterium bovis attached to oil droplets. J Natl Cancer Inst 1972;48:831-5.

${ }^{4}$ Baldwin RW, Pimm MV. Influence of BCG injection on growth of 3 methylcholanthane induced rat sarcomas. Rev Eur Études Clin Biol 1971;16:875-81.

5 Mathé G, Amiel JL, Schwarzenberg L, et al. Active immunotherapy for acute lymphoblastic leukaemia. Lancet 1969;1:697-9.
${ }^{6}$ Morton DL, Eilber FR, Malmgren RA, Wood WC. Immunological factors which influence response to immunotherapy in malignant melanoma. Surgery 1970; 68:158-64.

7 Grant RM, Mackie R, Cochran AJ, Murray EL, Hoyle D, Ross C. Results of administering BCG to patients with melanoma. Lancet 1974;2:1096-100.

${ }^{8}$ Hersh EM, Gutterman JU, Mavligit GM. Immunotherapy of leukemia. Med Clin North Am 1976;60:101942.

${ }^{9}$ Morton DL, Holmes EC, Eilber FR, Sparks FC, Ramming KP. In: Terry WD, Windhorst D, eds. Immunotherapy of cancer: present status of trials in man. New York: Raven Press, 1978.

${ }^{10}$ Israel L. Preliminary results of non-specific immunotherapy for lung cancer. Cancer Chemother Rep 1973;4: Suppl 4, 283-6.

${ }^{11}$ Hersh EM, Gutterman JU, Mavligit GM. BCG as adjuvant therapy for neoplasia. Annu Rev Med 1977;28:489515.

12 McKneally MF, Maver C, Kausel HW. Regional immunotherapy of lung cancer with intrapleural BCG. Lancet 1976;1:377-9.

${ }^{13}$ Edwards FR, Whitwell F. Use of BCG as an immunostimulant in the surgical treatment of carcinoma of lung-a five year follow-up report. Thorax 1978;33: 250-2.

${ }^{14}$ Edwards FR. Use of BCG as an immunostimulant after resection of carcinoma of the lung - a two year assessment of a trial of 500 patients. Thorax 1979;34:801-6.

${ }^{15}$ Holmes EC, Ramming KP, Bein ME, Coulson WF, Callery CD. Intralesional BCG immunotherapy of pulmonary tumors. J Thorac Cardiovasc Surg 1979;77: 362-8.

16 Roscoe P, Pearce S, Ludgate S, Horne NW. A controlled trial of BCG immunotherapy in bronchogenic carcinoma treated by surgical resection. Cancer Immunol Immunother 1977;3:115-8.

${ }^{17}$ Barkas T, Al-Khateeb SF, Irvine WJ, Davidson NMcD, Roscoe P. Inhibition of antibody-dependent cell mediated cytotoxicity as a means of detection of immune complexes in the sera of patients with thyroid disorders and bronchogenic carcinoma. Clin Exp Immunol 1976;25: 270-9.

18 Barnes EW, Farmer A, Penhale WH, Irvine WJ, Roscoe P, Horne HW. Phytohemagglutin-induced lymphocyte transformation in newly presenting patients with primary carcinoma of the lung. Cancer 1975;36:187-93.

19 Mathé G. Surviving in company of BCG. Cancer Immunol Immunother 1976;1:3-6.

${ }^{20}$ Millar JW, Hunter AM, Wightman AJA, Horne NW. Intralesional injection of BCG using the fibreoptic bronchoscope in the treatment of bronchogenic carcinoma. Eur J Respir Dis 1980;61 :162-6. 